\title{
Pitavastatin attenuates monocyte activation in response to orthopedic implant-derived wear particles by suppressing the NF- $\mathrm{KB}$ signaling pathway
}

\author{
ZEHUA ZHANG $^{1}$, FEI DAI ${ }^{1}$, PENG CHENG ${ }^{1}$, FEI LUO ${ }^{1}$, TIANYONG HOU ${ }^{1}$, \\ QIANG ZHOU ${ }^{1}, \mathrm{ZHAO} \mathrm{XIE}^{1}, \mathrm{MOYUAN}^{\mathrm{NENG}}{ }^{2}$ and JIAN-ZHONG XU ${ }^{1}$ \\ ${ }^{1}$ Department of Orthopaedics; ${ }^{2}$ National and Regional United Engineering Laboratory of Tissue Engineering, \\ Southwest Hospital, Third Military Medical University, Chongqing 400038, P.R. China
}

Received October 20, 2014; Accepted July 7, 2015

DOI: $10.3892 / \mathrm{mmr} .2015 .4306$

\begin{abstract}
Aseptic loosening secondary to particle-induced periprosthetic osteolysis is considered to be the primary cause of long-term implant failure in orthopedic surgery. Implant-derived wear particles activate and recruit macrophages and osteoclasts, which cause a persistent inflammatory response with bone destruction that is followed by a loosening of the implant. Thus, strategies for inhibiting macrophage and osteoclast function may provide a therapeutic benefit for preventing aseptic loosening. The aim of the present study was to determine the effects of pitavastatin on the activation and cytokine response of polymethyl methacrylate (PMMA) particle-induced monocytes. Peripheral blood monocytes were obtained and treated with PMMA and pitavastatin. ELISA demonstrated that pitavastatin inhibited mRNA and protein expression of interleukin (IL)-1 $\beta$, IL-6 and tumor necrosis factor- $\alpha$. Western blot analysis and immunofluorescence staining demonstrated that pitavastatin downregulated inhibitor of $\kappa \mathrm{B}$ phosphorylation and degradation, and nuclear factor $\kappa$-light-chain-enhancer of activated B cells $(\mathrm{NF}-\kappa \mathrm{B}) \mathrm{p} 65$ translocation. Together, these results indicate that pitavastatin may attenuate monocyte activation in response to orthopedic implant wear particles by suppression of the $\mathrm{NF}-\kappa \mathrm{B}$ signaling pathway.
\end{abstract}

\section{Introduction}

Total joint replacement (TJR), by the implantation of permanent prosthetic components, is currently considered to be a particularly successful clinical procedure in orthopedic

Correspondence to: $\mathrm{Dr}$ Jian-Zhong Xu, Department of Orthopaedics, Southwest Hospital, Third Military Medical University, 29 Gaotanyan Main Street, Chongqing 400038, P.R. China

E-mail: xujianzhongtg@163.com

Key words: pitavastatin, periprosthetic osteolysis, wear particles, monocyte, nuclear factor $\kappa$-light-chain-enhancer of activated B cells surgery (1). However, wear particle-induced periprosthetic osteolysis and subsequent aseptic loosening continue to be major causes of arthroplasty failure (2). Implant-derived wear particles activate and recruit macrophages and osteoclasts around and at the implant-host interface (3). These cells secrete high levels of inflammatory cytokines, such as interleukin (IL)-1 $\beta$, IL-6, and tumor necrosis factor (TNF)- $\alpha$ that mediate and accelerate the inflammatory and osteolytic responses, which result in the loosening and subsequent failure of bone implants (4). Thus, the application of pharmacological agents for the prevention of this osteolytic response to wear debris has attracted significant interest, with particular emphasis on anti-inflammatory agents.

Pitavastatin, a 3-hydroxy-3-methylglutaryl coenzyme A (HMG CoA) reductase inhibitor, effectively modifies atherogenic lipid profiles and thereby reduces cardiovascular risk in individuals presenting with dyslipidemia and cardiometabolic diseases (5). Unlike other statins, the characteristic structure of pitavastatin provides improved pharmacokinetics and significant low-density lipoprotein cholesterol-lowering efficacy at low doses (6). In addition, increasing evidence indicates that pitavastatin exhibits numerous pleiotropic effects beyond its lipid-lowering potencies. In a previous study, pitavastatin at a low dose $(1 \mu \mathrm{M})$ inhibited nuclear factor $\kappa$-light-chain-enhancer of activated $B$ cells $(N F-\kappa B)$ activation and decreased IL- 6 production, which was induced by TNF- $\alpha$ in human breast cancer cells (7). Takano et al (8) demonstrated that pitavastatin prevented acute lung injury development in septic mice by increasing glucocorticoid receptor expression and downregulating $\mathrm{NF}-\kappa \mathrm{B}$ activation in alveolar macrophages. Katsuki et al (9) showed that pitavastatin treatment inhibited atherosclerotic plaque destabilization and rupture in a mouse model of diet-induced lipodystrophy by regulating monocyte chemoattractant protein-1/C-C chemokine receptor type 2-dependent monocyte recruitment. Furthermore, various clinical studies identified that pitavastatin therapy significantly decreased in-hospital or 28-day mortality in patients exhibiting infection and sepsis (10). However, pitavastatin has not been considered as an effective tool with therapeutic potential in the prevention of osteolysis in response to orthopedic wear particles. 
The present study investigated whether treatment with pitavastatin (a new synthetic statin drug) was able to alleviate the activation of the monocyte inflammatory response induced by polymethyl methacrylate (PMMA) particles. The production of pro-inflammatory cytokines and the intracellular $\mathrm{NF}-\kappa \mathrm{B}$ signaling pathway were also examined to identify the role of pitavastatin in monocyte activation..

\section{Materials and methods}

Preparation of PMMA particles and pitavastatin. Spherical PMMA particles (Polysciences, Inc., Warrington, PA, USA) $1-10 \mu \mathrm{m}$ in diameter (mean diameter, $6.0 \mu \mathrm{m} ; 95 \%<10 \mu \mathrm{m}$ ) were used for all experiments as previously reported (11-13). The particles were rinsed four times in $70 \%$ ethanol, sterilized in $70 \%$ ethanol (Sigma-Aldrich, St. Louis, MO, USA) overnight, then washed four times in sterile phosphate-buffered saline (PBS; Wuhan Boster Biological Technology, Ltd., Wuhan, Hubei, China). Particles were resuspended in serum-free Minimum Essential Medium (MEM; Life Technologies, Grand Island, NY, USA) and stored at $-20^{\circ} \mathrm{C}$. A Limulus Amebocyte Lysate kit (BioWhittaker, Walkersville, MD, USA) was used to detect bacterial endotoxins. The optimal PMMA particle concentration for cell culture experiments was identified to be $2 \mathrm{mg} / \mathrm{ml}$. The pitavastatin (Sigma-Aldrich) was stored at $-20^{\circ} \mathrm{C}$ until it was diluted in serum-free MEM immediately prior to use.

Monocyte isolation. Peripheral whole blood was obtained from healthy volunteers $(\mathrm{n}=12)$ into heparinized bottles (Shandong Weigao Group Medical Polymer Co., Ltd., Weihai, China). The twelve subjects recruited for the study were healthy male volunteers aged between 23-45 years. All volunteers enrolled in the present study provided written informed consent. Blood collection was conducted between January and June 2014 at the Southwest Hospital of the Third Military Medical University (Chongqing, China). The heparinized blood was diluted in equal volumes of $10 \mathrm{ml}$ Dulbecco's modified Eagle's medium (Gibco Life Technologies, Carlsbad, CA, USA) supplemented with $10 \%$ fetal bovine serum (Gibco Life Technologies) and maintained at $37^{\circ} \mathrm{C}$. The $20 \mathrm{ml}$ of diluted blood samples were then layered onto $10 \mathrm{ml}$ of Ficoll-Paque PLUS (GE Healthcare Bio-Sciences, Uppsala, Sweden) and centrifuged at $500 \mathrm{x} \mathrm{g}$ for $30 \mathrm{~min}$. The buffer mononuclear layer was removed and washed three times with PBS, and then plated in 12-well plates (Corning Incorporated, Corning, NY, USA) in $5 \times 10^{5} / \mathrm{ml}$ Dulbecco's modified Eagle's medium supplemented with $10 \%$ fetal bovine serum. All steps were carried out at room temperature. The monocyte population was allowed to adhere for $120 \mathrm{~min}$ at $37^{\circ} \mathrm{C}$ in an atmosphere of $5 \% \mathrm{CO}_{2}$. Cells (lymphocytes) that had not adhered were subsequently washed off using PBS and the remaining monocyte population was used.

Measurement of cytokines. Monocytes were treated with various concentrations of PIT $(0-100 \mu \mathrm{M})$ together with $2 \mathrm{mg} / \mathrm{ml}$ PMMA for $12 \mathrm{~h}$. The culture medium was subsequently collected and the concentrations of TNF- $\alpha$, IL- $1 \beta$ and IL-6 were measured using a commercially available ELISA kit (Wuhan Boster Biological Technology, Ltd.) according to the manufacturer's instructions. The absorbance was measured at
$450 \mathrm{~nm}$ using a microplate reader (Bio-Tek ELX800; Bio-Tek Instruments, Inc., Winooski, VT, USA).

Reverse transcription-quantitative polymerase chain reaction (RT-qPCR) assay. Total cellular RNA was isolated using TRIzol (Invitrogen Life Technologies, Camarillo, CA, USA) and cDNA was synthesized using SuperScript ${ }^{\circledR}$ Reverse Transcriptase (Invitrogen Life Technologies) according to the manufacturer's instructions. The primer sequences (Shanghai Shenggong Co.,Ltd., Shanghai, China) used in the present study were as follows: Forward, 5'-CGAGTCTGGGCAGGTCTA-3' and reverse, 5'-CGAAGTGGTGGTCTTGTTG-3' for TNF- $\alpha$; forward, 5'-CTTCAGGCAGGCAGTATCACTC-3' and reverse, 5'-TGCAGTTGTCTAATGGGAACGT-3' for IL-1 $\beta$; forward, 5'-TCAATGAGGAGACTTGCCTG-3' and reverse, 5'-GATGAGTTGTCATGTCCTGC-3' for IL-6; and forward, 5'-TCACCACCATGGAGAAGGC-3' and reverse, 5'-GCTAAGCAGTTGGTGGTGCA-3' for GAPDH. RT-qPCR was performed using a LightCyclerH 480 Instrument (Roche Diagnostics GmbH, Mannheim, Germany) and SYBR ${ }^{\circledR}$ Green SuperMix (Sigma-Aldrich). The amplification program included an initial denaturation step at $95^{\circ} \mathrm{C}$ for $5 \mathrm{~min}$ and 45 cycles (each consisting of denaturation at $95^{\circ} \mathrm{C}$ for $10 \mathrm{sec}$ ), annealing at $60^{\circ} \mathrm{C}$ for $10 \mathrm{sec}$ and extension at $72^{\circ} \mathrm{C}$ for $10 \mathrm{sec}$. The comparative cycle threshold $(\mathrm{Ct})$ method $\left(2^{-\Delta \Delta \mathrm{CT}}\right)$ was used to calculate relative gene expression. The results were expressed as the fold change over the control values.

Western blotting. Cells were collected and lysed in radioimmunoprecipitation assay buffer (Sigma-Aldrich) supplemented with a Broad Spectrum Protease Inhibitor Cocktail (BD Pharmingen, San Diego, CA, USA). Following centrifugation for $10 \mathrm{~min}$ at $10,000 \mathrm{x} \mathrm{g}$, the protein content of the supernatant was determined using a bicinchoninic acid assay kit (Beyotime Institute of Biotechnology, Shanghai, China). The protein lysates were separated by $10 \%$ SDS-PAGE (Beyotime Institute of Biotechnology) and subsequently electrotransferred onto a polyvinylidene difluoride membrane (EMD Millipore, Billerica, MA, USA). The membrane was blocked with $5 \%$ bovine serum albumin (Sigma-Aldrich) for $1 \mathrm{~h}$ at room temperature. The blocked membranes were incubated overnight at $4^{\circ} \mathrm{C}$ with the following primary antibodies: Rabbit anti-NF- $\mathrm{B}$ monoclonal antibody (1:600; cat. no. sc-372), rabbit anti-p-inhibitor of $\kappa \mathrm{B}(\mathrm{I} \kappa \mathrm{B})$ monoclonal antibody (1:600; cat. no. sc-101713), rabbit anti-IкB monoclonal antibody (1:600; cat. no. sc-371), rabbit anti-GADPH monoclonal antibody (1:1,000; cat. no. sc-25778) and rabbit anti-TATA box binding protein monoclonal antibody $(1: 1,000$; cat. no. sc-33736), which were all purchased from Santa Cruz Biotechnology, Inc. (Dallas, TX, USA). The membranes were then incubated with horseradish peroxidase-linked goat anti-rabbit immunoglobulin G (1:10,000; Cell Signaling Technology, Inc., Danvers, MA, USA) for $1 \mathrm{~h}$ at room temperature. Protein bands were visualized using a western blotting detection system (ChemiDoc ${ }^{\mathrm{TM}}$ XRS+; Bio-Rad Laboratories, Hercules, CA, USA) and analyzed by a densitometry system (Quantity One v4.6.2; Bio-Rad Laboratories) according to the manufacturer's instructions.

For extraction of the nucleoprotein, cells were collected and lysed in the lysis buffer [10 mM Hepes (pH 7.9), $1.5 \mathrm{mM}$ 

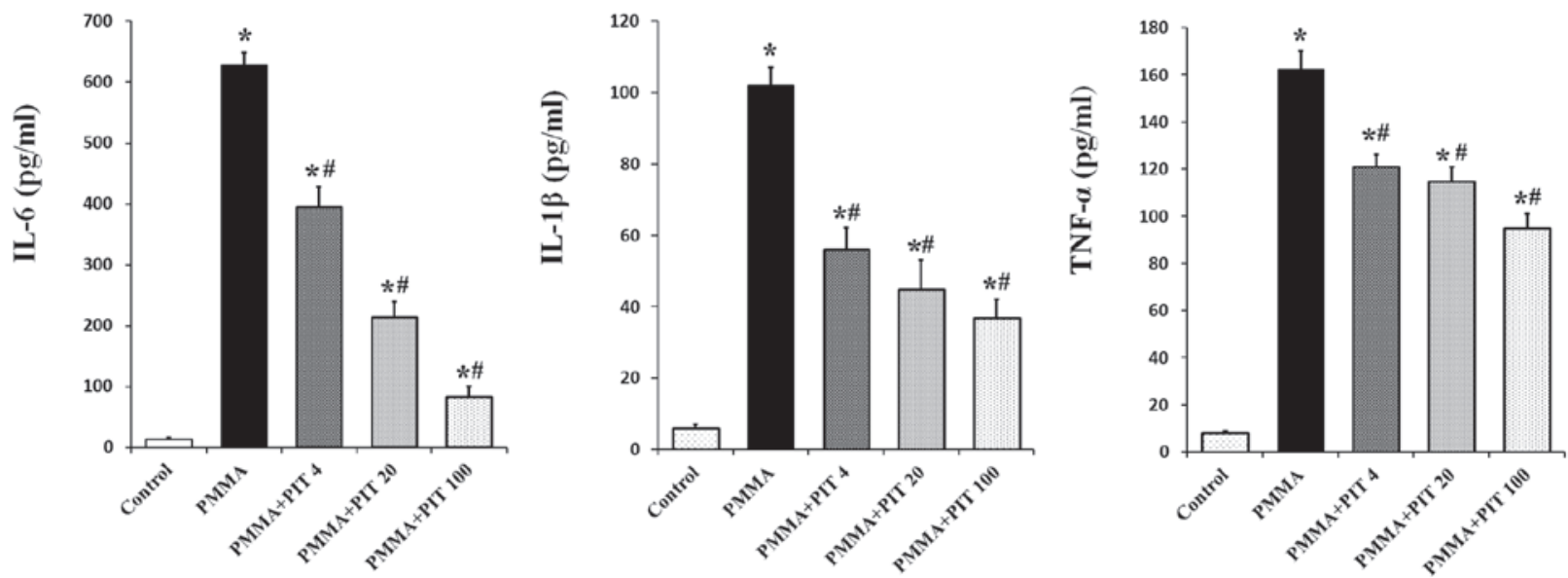

Figure 1. Effects of PIT on PMMA-induced production of pro-inflammatory cytokines. Monocytes were treated with different concentrations of PIT $(4,20$ and $100 \mu \mathrm{M}$ ) together with $2 \mathrm{mg} / \mathrm{ml}$ PMMA for $12 \mathrm{~h}$. TNF- $\alpha$, IL- $1 \beta$ and IL- 6 in supernatants were measured by ELISA. Results are presented as means \pm standard deviation for three independent experiments. "P $<0.05$ vs. the control group. ${ }^{*} \mathrm{P}<0.05$ vs. the PMMA group. PIT, pitavastatin; PMMA, polymethylmethacrylate; TNF, tumor necrosis factor; IL, interleukin.

$\mathrm{MgCl}_{2}, 10 \mathrm{mM} \mathrm{KCl}, 0.5 \mathrm{mM}$ dithiothreitol, $2 \% \mathrm{NP}-40$, $1 \mathrm{mM}$ phenylmethylsulfonyl fluoride] (Beyotime Institute of Biotechnology) for $20 \mathrm{~min}$, and the lysis buffer was centrifuged at $1,000 \mathrm{x} \mathrm{g}$ for $10 \mathrm{~min}$. The protein content of the supernatant was collected as the cytoplasmic protein. The precipitate was washed twice and lysed in lysis buffer containing Triton X-100 (Sigma-Aldrich) and collected as the nucleoprotein.

Immunofluorescence. Monocytes were seeded onto 12-well plates, grown in chamber slides and treated with $2 \mathrm{mg} / \mathrm{ml}$ PMMA and/or $100 \mathrm{mM}$ pitavastatin for $1 \mathrm{~h}$. Cells were fixed with 4\% paraformaldehyde (Nanjing Jiancheng Bioengineering Institute, Nanjing, China) and permeabilized with $0.5 \%$ Triton $\mathrm{X}-100$. Immunostaining of p65 was performed using rabbit anti-p65 monoclonal antibody (cat. no. sc-372; Santa Cruz Biotechnology, Inc.) at a dilution of 1:200, then with fluorescein isothiocyanate-conjugated goat anti-rabbit immunoglobulin $\mathrm{G}$ secondary antibody (Abcam, Cambridge, MA,USA) at a dilution of 1:5,000. Finally, the cells were stained with DAPI (Beyotime Institute of Biotechnology) for $10 \mathrm{~min}$ to localize the nuclei, which served as a reference point. For the negative controls, the primary antibodies were excluded from the staining procedure described above. The activation of NF-kB was defined by its translocation into the nucleus, which was visualized by fluorescence microscopy (magnification, x20) using a Nikon Eclipse E1000 (Nikon Corporation, Tokyo, Japan).

Statistical analysis. All results are expressed as the mean \pm standard deviation. The results were analyzed by analysis of variance, followed by Student's t-test to determine the significance. $\mathrm{P}<0.05$ was considered to indicate a statistically significant difference. All the statistical analyses were performed using the SPSS 12.0 statistical software (SPSS, Inc., Chicago, IL, USA).

\section{Results}

Pitavastatin inhibits PMMA-induced pro-inflammatory cytokine production. PMMA particles are widely derived from implants used in TJR, as they result from wear of the material in the prosthetic. Thus, in the present study, PMMA particles served as a stimulant to trigger inflammatory monocytes. Varying concentrations of PMMA (1,2 and $4 \mathrm{mg} / \mathrm{ml})$ were added into the monocyte culture medium 6,12 or $24 \mathrm{~h}$ prior to analysis. It was found that in all of the PMMA concentration groups, the pro-inflammatory cytokines were increased in a time-dependent manner and there was no significant differences noted between the 2 and $4 \mathrm{mg} / \mathrm{ml}$ PMMA groups (data not shown). Therefore, a PMMA particle concentration of $2 \mathrm{mg} / \mathrm{ml}$ was selected and administered $24 \mathrm{~h}$ prior to the cell culture experiments.

To study the effect of pitavastatin, $2 \mathrm{mg} / \mathrm{ml}$ PMMA was applied to stimulate the monocytes, and $0-100 \mu \mathrm{M}$ pitavastatin was simultaneously administrated. After $24 \mathrm{~h}$, as seen in Fig. $1,2 \mathrm{mg} / \mathrm{ml}$ PMMA induced a significant production of TNF- $\alpha$, IL-1 $\beta$ and IL-6 in the monocytes $(\mathrm{P}<0.05)$. However, pitavastatin treatment significantly inhibited the production of pro-inflammatory cytokines in a dose-dependent manner $(\mathrm{P}<0.05)$.

Pitavastatin inhibits PMMA-induced TNF- $\alpha, I L-1 \beta$ and IL-6 mRNA expression. RT-qPCR was conducted to assess whether pitavastatin inhibits TNF- $\alpha$, IL-1 $\beta$ and IL-6 mRNA expression. As demonstrated in Fig. 2, PMMA stimulation of monocytes resulted in a marked increase in TNF- $\alpha$, IL-1 $\beta$ and IL- 6 at the transcriptional level. However, treatment with varying concentrations of pitavastatin $(4,20$ and $100 \mu \mathrm{M})$ significantly downregulated PMMA-induced transcription of TNF- $\alpha$, IL-1 $\beta$ and IL- 6 mRNA in a concentration-dependent manner $(\mathrm{P}<0.05)$.

Pitavastatin inhibits PMMA-induced I $\kappa$ B phosphorylation and degradation. NF- $\mathrm{\kappa B}$ is considered to be a master switch in the regulation of inflammation and immunity (14). As a transcription factor, NF- $\mathrm{kB}$ controls an array of pro-inflammatory genes involved in the inflammatory signaling cascade, such as TNF- $\alpha$, IL-1 $\beta$, and IL-6 (15). Therefore, the effect of pitavastatin on PMMA-induced NF- $\kappa \mathrm{B}$ activation in monocytes 

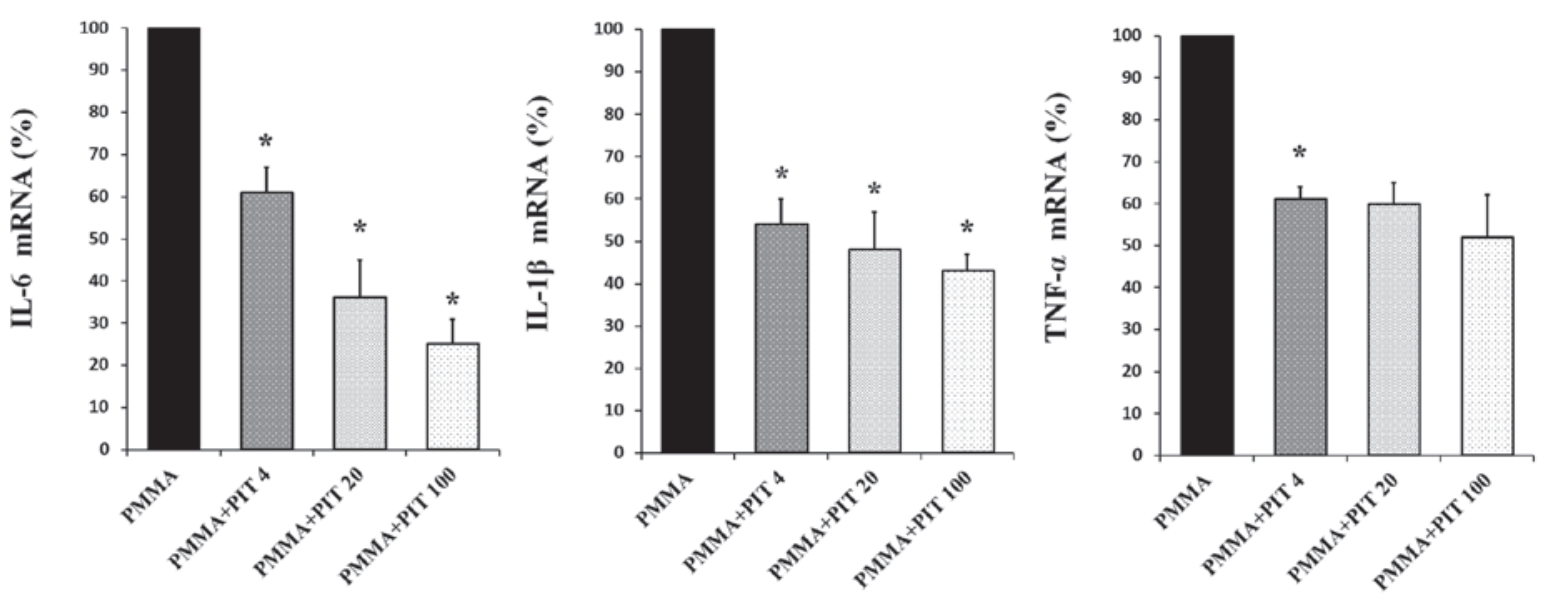

Figure 2. Effects of PIT on PMMA-induced mRNA expression of TNF- $\alpha$, IL-1 $\beta$ and IL-6. Monocytes were treated with different concentrations of PIT (4, 20 and $100 \mu \mathrm{M}$ ) together with $2 \mathrm{mg} / \mathrm{ml}$ PMMA for $5 \mathrm{~h}$. The mRNA expression levels of TNF- $\alpha$, IL-1 $\beta$ and IL- 6 were detected by reverse transcription-quantitative polymerase chain reaction. Results are presented as means \pm standard deviation for three independent experiments. "P $<0.05$ vs. the PMMA group. PIT, pitavastatin; PMMA, polymethylmethacrylate; TNF, tumor necrosis factor; IL, interleukin.
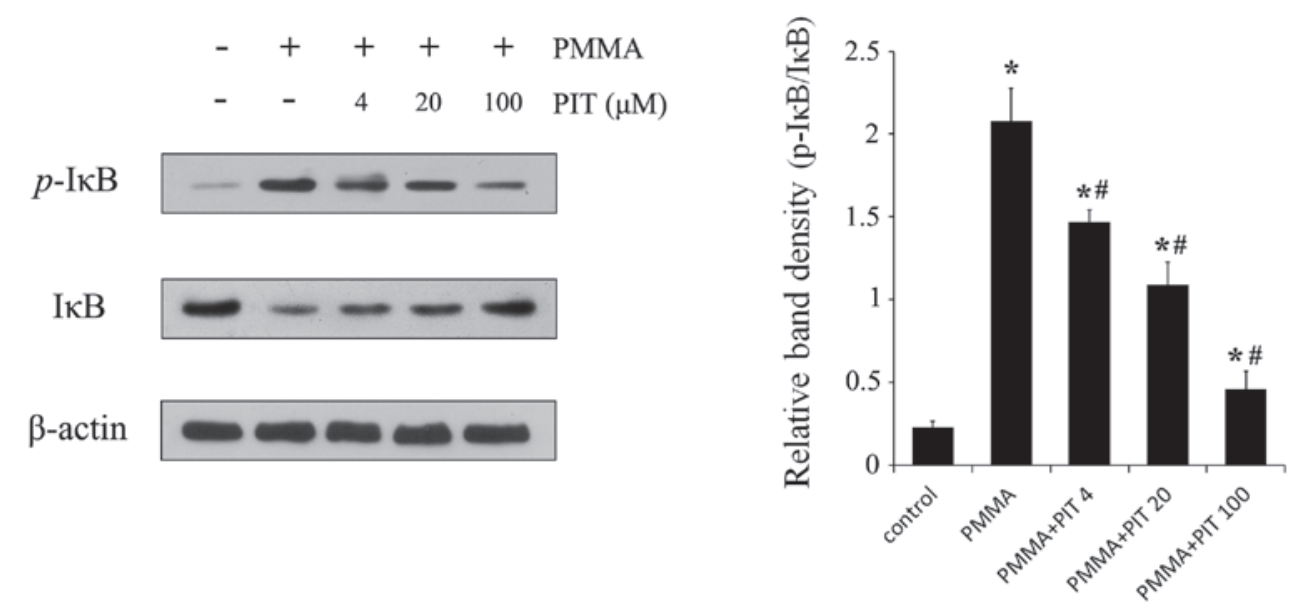

Figure 3. Effects of PIT on PMMA-induced IкB phosphorylation and degradation. Monocytes were treated with different concentrations of PIT (4, 20 and $100 \mu \mathrm{M}$ ) together with $2 \mathrm{mg} / \mathrm{ml}$ PMMA for 30 min. Cells were collected and lysed. IкB and $\mathrm{p}$-I $\mathrm{kB}$ were determined by western blotting. The expression

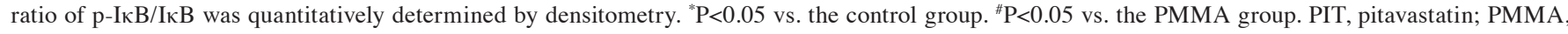
polymethylmethacrylate; $\mathrm{p}$, phosphorylated.

were investigated. As shown in Fig. 3, monocytes treated with PMMA exhibited significant phosphorylation of IкB, whereas the various treatment concentrations of pitavastatin $(4,20$ and $100 \mu \mathrm{M})$ prevented IкB phosphorylation. In addition, pitavastatin inhibited degradation of I $\mathrm{B}$, which had been induced by PMMA, in a concentration-dependent manner. These results indicate that pitavastatin significantly blocks the NF- $\kappa B$ signaling pathway in PMMA-stimulated monocytes by suppressing IкB phosphorylation and degradation.

Pitavastatin inhibits PMMA-induced NF- $\kappa B$ p65 translocation. Having established that pitavastatin inhibits IкB phosphorylation and degradation, further investigations regarding its effects on NF- $\mathrm{KB}$ signaling were performed. The p65 protein levels in the cytoplasmic and nuclear fractions of PMMA-induced monocytes were analyzed. As shown in Fig. 4, PMMA stimulation resulted in significant nuclear translocation of p65 in the monocytes, whereas pitavastatin treatment prevented the accumulation of PMMA-induced nuclear p65 in a concentration-dependent manner. Furthermore, immunocytochemical analysis demonstrated that pitavastatin treatment exhibited reduced nuclear translocation of endogenous p65 following PMMA stimulation (Fig. 5). These results indicate that pitavastatin significantly inhibits NF- $\mathrm{kB}$ p65 translocation in PMMA-stimulated monocytes.

\section{Discussion}

TJR is considered to be the most effective treatment strategy for end-stage joint diseases, such as osteoarthritis and rheumatoid arthritis (16). However, despite the clinical effectiveness of TJR, aseptic loosening of prostheses continues to present a major problem, particularly for the long-term success and survival of a prosthesis (17). There are various causes of aseptic loosening, however, an inflammatory reaction induced by excessive production of wear particles from the implant components and consequent peri-implant osteolysis is regarded as the primary cause (18). 

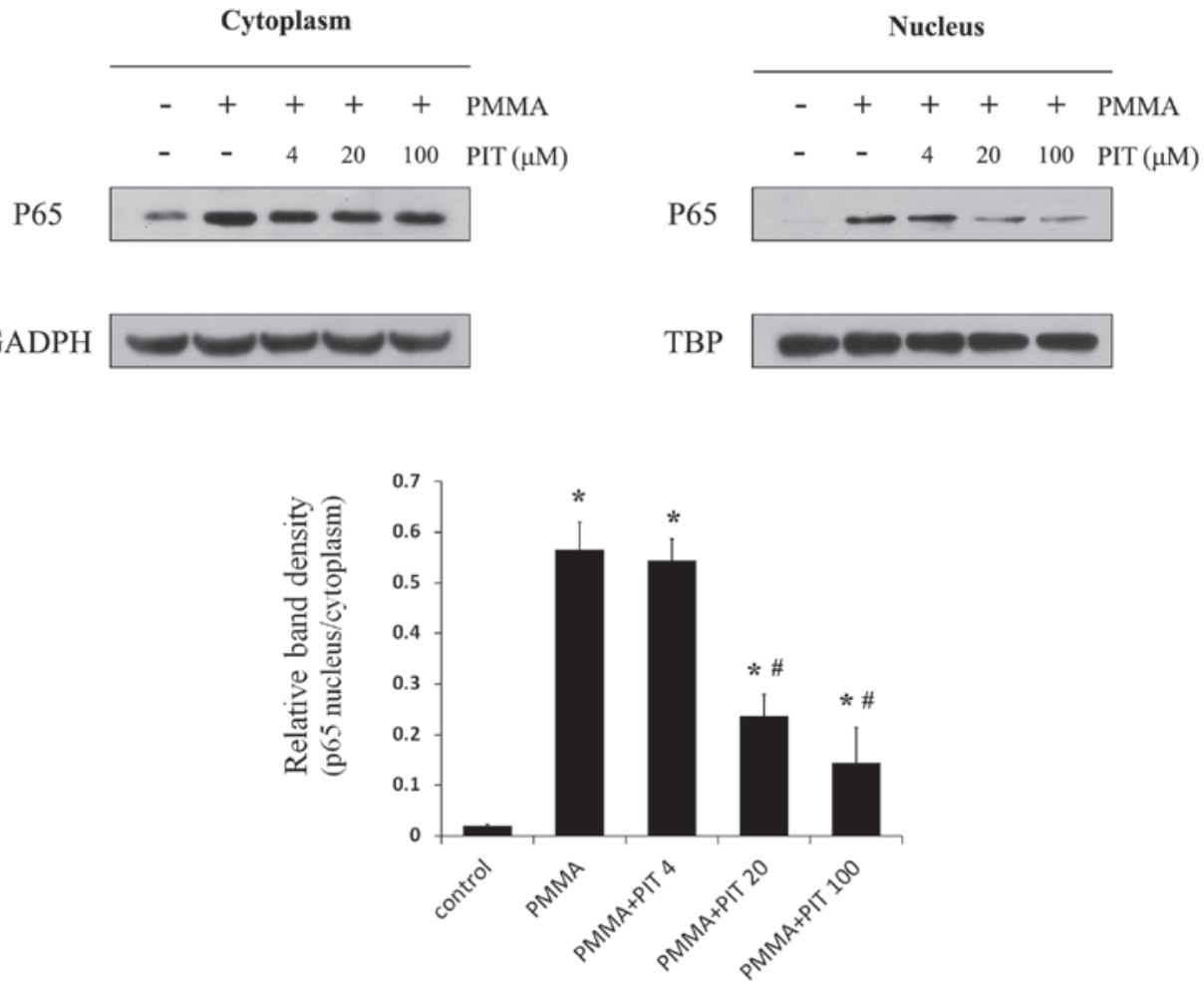

Figure 4. Effects of PIT on PMMA-induced NF- $\mathrm{BB}$ p65 translocation. Monocytes were treated with different concentrations of PIT $(4,20$ and $100 \mu \mathrm{M})$ together with $2 \mathrm{mg} / \mathrm{ml}$ PMMA for $30 \mathrm{~min}$. Cells were collected and lysed, and the levels of NF- $\mathrm{kB}$ p65 in the cytoplasm and nucleus were determined by western blotting. The ratio of nuclear p 65 to cytoplasmic $\mathrm{p} 65$ was quantitatively determined by densitometry. ${ }^{*} \mathrm{P}<0.05$ vs. the control group. ${ }^{~} \mathrm{P}<0.05$ vs.

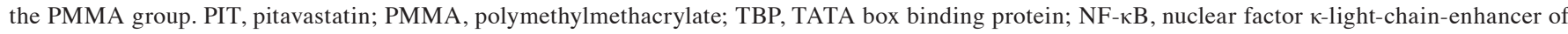
activated B cells.

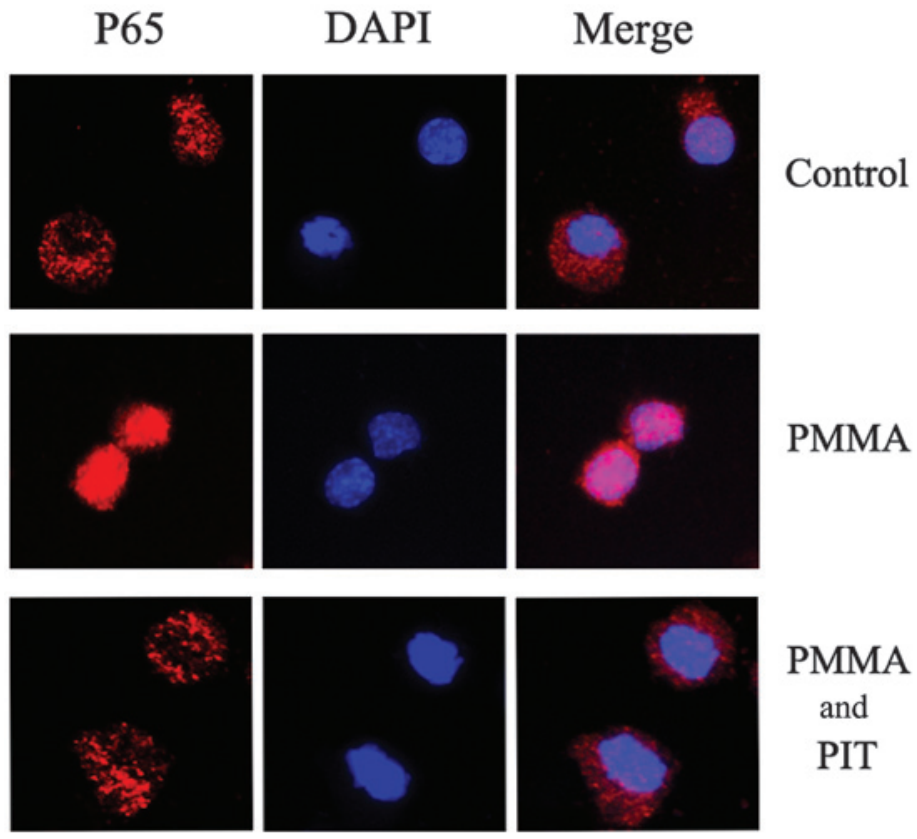

Figure 5. Effects of PIT on NF-кB p65 translocation induced by PMMA. Monocytes were seeded onto 12-well plates, grown in chamber slides and treated with $2 \mathrm{mg} / \mathrm{ml}$ PMMA and/or $100 \mathrm{mM}$ PIT for $1 \mathrm{~h}$. NF- $\mathrm{kB}$ p65 translocation was measured by immunofluorescence microscopy. Magnification, x600. PIT, pitavastatin; PMMA, polymethylmethacrylate; NF- $\mathrm{B}$, nuclear factor $\kappa$-light-chain-enhancer of activated B cells.

PMMA particles, a material widely derived from orthopedic implants, elicit a marked inflammatory response due to macrophage and enhanced osteoclast formation and activity (19-21). Upon exposure to PMMA, osteoblasts contribute to periprosthetic osteolysis by secreting mediators that drive the inflammatory process (22). These mediators, which include TNF- $\alpha$, IL-1 $\beta$ and IL-6, interact with one another contributing significantly to the inflammatory cascade. 
TNF- $\alpha$ is considered to be a key cytokine, which mediates particle-driven osteoclastogenesis and osteolysis (23). TNF- $\alpha$ increases osteoclast differentiation by promoting the expression of receptor activation of $N F-\kappa B$ ligand and macrophage-colony stimulating factor, which are essential factors involved in the expansion, commitment and differentiation of osteoclast precursors into mature osteoclasts $(24,25)$. Fuller et al (26) demonstrated that a low level concentration of TNF- $\alpha$ stimulation activates osteoclasts and indicated that this effect cannot be inhibit by osteoprotegerin. Furthermore, an adenovirus-mediated small interfering RNA targeting TNF- $\alpha$ was observed to significantly inhibit titanium wear particle-induced osteoclastogenesis and bone resorption in macrophages (27). IL-1 $\beta$ is also a well-established pro-inflammatory cytokine that contributes to aseptic loosening. As an important downstream molecule in TNF- $\alpha$-induced osteoclast differentiation, IL-1 $\beta$ promotes multinucleation of osteoclast progenitor cells and enhances mature osteoclast-associated bone resorption (28-30). Therefore, controlling the synthesis of inflammatory cytokines in the periprosthetic environment may be a potential target for the prevention or reduction of wear particle-induced osteolysis. In addition, the anti-inflammatory effects of statins are well recognized. Uekawa et al (31) indicated that statin pretreatment ameliorated early brain injury, following a subarachnoid hemorrhage, via the attenuation of oxidative stress and NF- $\kappa \mathrm{B}$-mediated inflammation. Moon et al (32) reported that short-term administration of statins to patients who had suffered an atherosclerotic stroke exerts antioxidant effects against lipid peroxidation via lipid-lowering-dependent and -independent mechanisms. McGuire et al (33) demonstrated that healthy male subjects who were administered with statins for three weeks showed a decline in TNF- $\alpha$ plasma concentrations and toll-like receptor-4 expression in blood monocytes. A meta-analysis of observational studies demonstrated that, although the use of statins did not significantly decrease the in-hospital or 28-day mortality, it did present a survival advantage in patients with infection and sepsis (10). Thus, it is hypothesized that statins may inhibit wear particle-induced inflammatory reactions from implant components.

The ability of pitavastatin to abrogate PMMA-mediated monocyte activation was examined in the present study. The peripheral blood monocyte/macrophage model is a well-recognized in vitro model for particle stimulation. Therefore, this was considered to be the most appropriate model for the established primary instigators of foreign-body inflammatory response and subsequent osteolysis, as monocytes represent the circulatory precursors of tissue macrophages. In the current study, stimulation of monocytes with $2 \mathrm{mg} / \mathrm{ml}$ PMMA resulted in a marked increase in TNF- $\alpha$, IL-1 $\beta$ and IL- 6 at the transcriptional and translational levels. However, pitavastatin treatment significantly downregulated the PMMA-induced TNF- $\alpha$, IL-1 $\beta$ and IL- 6 expression at the transcriptional and translational levels in a concentration-dependent manner (Figs. 1 and 2).

PMMA particles are potent inducers of the NF- $\kappa \mathrm{B}$ signaling pathway, which is considered to be an important mediator of inflammatory responses, and essential for osteoclast differentiation and function (34). In its inactivated state, $\mathrm{NF}-\kappa \mathrm{B}$ is located in the cytoplasm as an inactive $\mathrm{NF}-\kappa \mathrm{B} / \mathrm{I} \kappa \mathrm{B}$ complex, and its activity is tightly controlled by the inhibitory

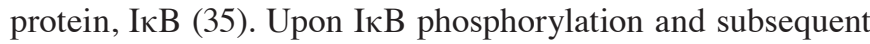
degradation, NF- $\kappa \mathrm{B}$ p65 is released and enters the nucleus to activate specific target gene expression. Therefore, the activation of $\mathrm{NF}-\kappa \mathrm{B}$ was assessed in monocytes in the present study by measuring the quantity of $\mathrm{I} \kappa \mathrm{B}$ protein expression. Incubation of monocytes with PMMA caused marked phosphorylation and degradation of cytosolic I $\kappa$ B, and NF- $\kappa$ B p65 translocation into the nucleus, whereas pitavastatin treatment significantly inhibited the phosphorylation and degradation of $\mathrm{I} \kappa \mathrm{B}$, as well as $\mathrm{NF}-\kappa \mathrm{B}$ p65 nuclear translocation in a dose-dependent manner (Figs. 3-5). This suggests that pitavastatin may suppress PMMA-induced activation of the $\mathrm{NF}-\kappa \mathrm{B}$ signaling pathway, indicating that the $\mathrm{NF}-\kappa \mathrm{B}$ pathway may be involved in the anti-inflammatory effects of pitavastatin.

In conclusion, pitavastatin has been demonstrated to inhibit PMMA-induced monocyte activation and inflammatory cytokine release by inhibiting phosphorylation and degradation of I $\mathrm{B}$, and subsequent NF- $\mathrm{B}$ p 65 translocation. Considering these findings, pitavastatin may be an efficacious candidate for administration as a therapeutic agent for periprosthetic osteolysis and aseptic loosening, which occur following TJR.

\section{References}

1. Snow R, Granata J, Ruhil AV, Vogel K, McShane M and Wasielewski R: Associations between preoperative physical therapy and post-acute care utilization patterns and cost in total joint replacement. J Bone Joint Surg Am 96: e165, 2014.

2. Gallo J, Goodman SB, Konttinen YT and Raska M: Particle disease: Biologic mechanisms of periprosthetic osteolysis in total hip arthroplasty. Innate Immun 19: 213-224, 2013.

3. Pearl JI, Ma T, Irani AR, Huang Z, Robinson WH, Smith RL and Goodman SB: Role of the Toll-like receptor pathway in the recognition of orthopedic implant wear-debris particles. Biomaterials 32: 5535-5542, 2011.

4. Holt G, Murnaghan C, Reilly J and Meek RM: The biology of aseptic osteolysis. Clin Orthop Relat Res 460: 240-252, 2007.

5. Masana L: Pitavastatin in cardiometabolic disease: Therapeutic profile. Cardiovasc Diabetol 12 (Suppl 1): S2, 2013.

6. Saito Y: Pitavastatin: An overview. Atheroscler Suppl 12: 271-276, 2011.

7. Wang $\mathbf{J}$ and Kitajima I: Pitavastatin inactivates NF-kappaB and decreases IL-6 production through Rho kinase pathway in MCF-7 cells. Oncol Rep 17: 1149-1154, 2007.

8. Takano K, Yamamoto S, Tomita K, Takashina M, Yokoo H, Matsuda N, Takano Y and Hattori Y: Successful treatment of acute lung injury with pitavastatin in septic mice: Potential role of glucocorticoid receptor expression in alveolar macrophages. J Pharmacol Exp Ther 336: 381-390, 2011.

9. Katsuki S, Matoba T, Nakashiro S, Sato K, Koga J, Nakano K, Nakano Y, Egusa S, Sunagawa K and Egashira K: Nanoparticle-mediated delivery of pitavastatin inhibits atherosclerotic plaque destabilization/rupture in mice by regulating the recruitment of inflammatory monocytes. Circulation 129: 896-906, 2014.

10. Wan YD, Sun TW, Kan QC, Guan FX and Zhang SG: Effect of statin therapy on mortality from infection and sepsis: A meta-analysis of randomized and observational studies. Crit Care 18: R71, 2014.

11. Clohisy JC, Frazier E, Hirayama T and Abu-Amer Y: RANKL is an essential cytokine mediator of polymethylmethacrylate particle-induced osteoclastogenesis. J Orthop Res 21: 202-212, 2003.

12. Clohisy JC, Teitelbaum S, Chen S, Erdmann JM and Abu-Amer Y: Tumor necrosis factor-alpha mediates polymethylmethacrylate particle-induced NF-kappaB activation in osteoclast precursor cells. J Orthop Res 20: 174-181, 2002.

13. Clohisy JC, Yamanaka Y, Faccio R and Abu-Amer Y: Inhibition of IKK activation, through sequestering NEMO, blocks PMMA-induced osteoclastogenesis and calvarial inflammatory osteolysis. J Orthop Res 24: 1358-1365, 2006. 
14. Peng Q, Liu $\mathrm{H}$, Shi S and Li M: Lycium ruthenicum polysaccharide attenuates inflammation through inhibiting TLR4/NF- $\kappa B$ signaling pathway. Int J Biol Macromol 67: 330-335, 2014.

15. Li Q and Verma IM: NF-kappaB regulation in the immune system. Nat Rev Immunol 2: 725-734, 2002.

16. Grunfeld R, Aydogan U and Juliano P: Ankle arthritis: Review of diagnosis and operative management. Med Clin North Am 98: 267-289, 2014.

17. Gallo J, Goodman SB, Konttinen YT, Wimmer MA and Holinka M: Osteolysis around total knee arthroplasty: A review of pathogenetic mechanisms. Acta Biomater 9: 8046-8058, 2013

18. Liu X, Qu X, Wu C, Zhai Z, Tian B, Li H, Ouyang Z, Xu X, Wang W, Fan $\mathrm{Q}$, et al: The effect of enoxacin on osteoclastogenesis and reduction of titanium particle-induced osteolysis via suppression of JNK signaling pathway. Biomaterials 35: 5721-5730, 2014

19. Sabokbar A, Fujikawa Y, Murray DW and Athanasou NA Bisphosphonates in bone cement inhibit PMMA particle induced bone resorption. Ann Rheum Dis 57: 614-618, 1998.

20. Lohmann CH, Dean DD, Küster G, Casasola D, Buchhorn GH Fink U, Schwartz Z and Boyan BD: Ceramic and PMMA particles differentially affect osteoblast phenotype. Biomaterials 23: 1855-1863, 2002

21. Ramachandran R, Goodman SB and Smith RL: The effects of titanium and polymethylmethacrylate particles on osteoblast phenotypic stability. J Biomed Mater Res A 77: 512-517, 2006.

22. Zambonin G, Colucci S, Cantatore F and Grano M: Response of human osteoblasts to polymethylmetacrylate in vitro. Calcif Tissue Int 62: 362-365, 1998

23. Liu FX, Wu CL, Zhu ZA, Li MQ, Mao YQ, Liu M, Wang XQ, Yu DG and Tang TT: Calcineurin/NFAT pathway mediates wear particle-induced TNF- $\alpha$ release and osteoclastogenesis from mice bone marrow macrophages in vitro. Acta Pharmacol Sin 34: 1457-1466, 2013.

24. Crotti TN, Smith MD, Findlay DM, Zreiqat H, Ahern MJ, Weedon H, Hatzinikolous G, Capone M, Holding C and Haynes D: Factors regulating osteoclast formation in human tissues adjacent to peri-implant bone loss: Expression of receptor activator NFkappaB, RANK ligand and osteoprotegerin. Biomaterials 25: 565-573, 2004.

25. Jiang Y, Jia T, Gong W, Wooley PH and Yang SY: Effects of Ti, PMMA, UHMWPE and Co-Cr wear particles on differentiation and functions of bone marrow stromal cells. J Biomed Mater Res A 101: 2817-2825, 2013.
26. Fuller K, Murphy C, Kirstein B, Fox SW and Chambers TJ: TNFalpha potently activates osteoclasts, through a direct action independent of and strongly synergistic with RANKL. Endocrinology 143: 1108-1118, 2002.

27. Guo H, Zhang J, Hao S and Jin Q: Adenovirus-mediated small interfering RNA targeting tumor necrosis factor- $\alpha$ inhibits titanium particle-induced osteoclastogenesis and bone resorption. Int J Mol Med 32: 296-306, 2013

28. Quinn JM, Horwood NJ, Elliott J, Gillespie MT and Martin TJ: Fibroblastic stromal cells express receptor activator of NF-kappaB ligand and support osteoclast differentiation. J Bone Miner Res 15: 1459-1466, 2000.

29. García-López S, Villanueva R and Meikle MC: Alterations in the synthesis of IL- $1 \beta$, TNF- $\alpha$, IL- 6 and their downstream targets RANKL and OPG by mouse calvarial osteoblasts in vitro: Inhibition of bone resorption by cyclic mechanical strain. Front Endocrinol (Lausanne) 4: 160, 2013.

30. Simsa-Maziel S, Zaretsky J, Reich A, Koren Y, Shahar R and Monsonego-Ornan E: IL-1RI participates in normal growth plate development and bone modeling. Am J Physiol Endocrinol Metab 305: E15-E21, 2013.

31. Uekawa K, Hasegawa Y, Ma M, Nakagawa T, Katayama T, Sueta D, Toyama K, Kataoka K, Koibuchi N, Kawano T, et al: Rosuvastatin ameliorates early brain injury after subarachnoid hemorrhage via suppression of superoxide formation and nuclear factor-kappaB activation in rats. J Stroke Cerebrovasc Dis 23: 1429-1439, 2014.

32. Moon GJ, Kim SJ, Cho YH, Ryoo S and Bang OY: Antioxidant effects of statins in patients with atherosclerotic cerebrovascular disease. J Clin Neurol 10: 140-147, 2014.

33. McGuire TR, Kalil AC, Dobesh PP, Klepser DG and Olsen KM: Anti-inflammatory effects of rosuvastatin in healthy subjects: A prospective longitudinal study. Curr Pharm Des 20: 1156-1160, 2014.

34. Yamanaka Y,Karuppaiah K and Abu-Amer Y: Polyubiquitination events mediate polymethylmethacrylate (PMMA) particle activation of NF-kappaB pathway. J Biol Chem 286: 23735-23741, 2011.

35. Hayden MS and Ghosh S: NF-кB in immunobiology. Cell Res 21: 223-244, 2011 